\title{
Losses and energy efficiency of drive motors and systems
}

\section{Replacement of the Sankey diagram of power decrease in the direction of power flow by a diagram of power increase opposite to the direction of power flow opens a new perspective of research of drive motors and systems}

\author{
Zygmunt Paszota, Prof. \\ Gdansk University of Technology, Poland
}

\begin{abstract}
Losses and energy efficiency of every drive motor must be presented as functions of physical quantities independent of losses in the motor. Such quantities are speed and load required by the machine or device driven by the motor, changing in the drive operating field. Speed and load of the motor decide of the instantaneous useful power of the motor and also in a differentiated way of kinds and values of losses occurring in the motor. However, losses and energy efficiency of the hydrostatic drive motors and systems are evaluated by researchers and manufacturers as functions of parameters depending on the losses. The basic cause of such situation is the traditional, commonly accepted but erroneous, view of the power flow in the drive motors and systems represented by the Sankey diagram of power decrease in the direction of power flow. It is necessary to replace the Sankey diagram by the proposed diagram of increase of power in the motor and in the drive system in the direction opposite to the direction of power flow. The proposed view of losses and energy efficiency should be applied to all types of motor and drive systems. The aim of this paper is showing the resulting problems of the above postulates, exemplified by operation of a rotational displacement motor in a hydrostatic drive system. In order to make possible objective evaluation of the energy behaviour of different motor and system solutions and sizes, the losses and energy efficiency should be described and compared as dependent on the motor speed coefficient $\bar{\omega}_{M}$ and load coefficient $\bar{M}$ changing in the drive system operating field $\left(0 \leq \bar{\omega}_{M}<\bar{\omega}_{\text {Mmax }}, 0 \leq \bar{M}_{M}<\bar{M}_{\text {Mmax }}\right)$. The presented proposals open a new perspective of unavoidable research of drive motors and systems, making it possible to compare objectively the energy efficiency of different types of motors and drive systems.
\end{abstract}

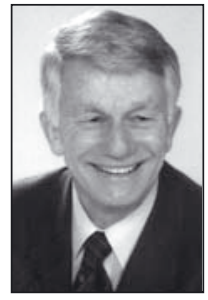

Key words: drive motors; drive systems; energy losses; energy efficiency; Sankey diagram; new research field

\section{INTRODUCTION}

Losses and energy efficiency of every drive motor must be presented as functions of physical quantities independent of losses in the motor. Such quantities are speed and load required by the machine or device driven by the motor, changing in the drive operating field. Speed and load of the motor decide of the instantaneous useful power of the motor and also in a differentiated way of kinds and values of losses occurring in the motor.

However, losses and energy efficiency of the drive motors and systems are evaluated by researchers and manufacturers as functions of parameters depending on the losses. An example of the wrong interpretation may be presentation of energy efficiencies of the hydrostatic rotational displacement motors as dependent on the flow intensity of the motor feeding liquid and on the pressure decrease of the motor.

Energy efficiency of turbines is presented in a similar way.

A cause of such situation is the traditional, commonly accepted but erroneous, view of the power flow in the drive motors and systems represented by the Sankey diagram of power decrease in the direction of power flow.

It is necessary to replace the Sankey diagram by the proposed diagram of increase of power in the motor and in the drive system in the direction opposite to the direction of power flow $[1 \div 23]$. 
The proposed view of losses and energy efficiency should be applied to all types of motor and drive systems, for instance:

- piston internal combustion motors,

- turbines,

- electric motors,

- hydrostatic displacement motors,

- ship screw propellers.

The aim of this paper is showing the resulting problems of the above postulates, exemplified by operation of a rotational displacement motor in a hydrostatic drive system.

In order to make possible objective evaluation of the energy behaviour of different motor and system solutions and sizes, the losses and energy efficiency should be described and compared as dependent on the motor speed coefficient $\bar{\omega}_{\mathrm{M}}$ and load coefficient $\overline{\mathrm{M}}_{\mathrm{M}}$ changing in the drive system operating field $\left(0 \leq \bar{\omega}_{\mathrm{M}}<\bar{\omega}_{\mathrm{Mmax}}, 0 \leq \overline{\mathrm{M}}_{\mathrm{M}}<\overline{\mathrm{M}}_{\mathrm{Mmax}}\right)$.

The presented proposals open a new perspective of unavoidable research of drive motors and systems, making it possible to compare objectively the energy efficiency of different types of motors and drive systems.

\section{INDEPENDENT AND DEPENDENT PARAMETERS OF A DRIVE MOTOR AND SYSTEM OPERATION, EXAMPLIFIED BY OPERATION OF A DISPLACEMENT MOTOR IN A HYDROSTATIC DRIVE SYSTEM}

The work of a rotational or linear hydraulic motor as an element of hydrostatic drive and control system, directly connected with the driven machine (device) must provide parameters required by the driven machine (angular speed $\omega_{\mathrm{M}}$ (rotational $n_{M}$ ) of the shaft or linear speed $v_{M}$ of the piston rod and shaft load (torque) $\mathrm{M}_{\mathrm{M}}$ or piston rod load (force) $\mathrm{F}_{\mathrm{M}}$ ) and also ensure the required machine movement direction.

The mechanical parameters of a motor $\left(\right.$ speed $\omega_{M}\left(n_{M}\right)$ or $\mathrm{v}_{\mathrm{M}}$ and also load $\mathrm{M}_{\mathrm{M}}$ or $\mathrm{F}_{\mathrm{M}}$ ) change in the range from zero to maximum values $\omega_{M \max }\left(\mathrm{n}_{\mathrm{M} \max }\right)$ or $\mathrm{v}_{\mathrm{M} \max }$ and $\mathrm{M}_{\mathrm{M} \max }$ or $\mathrm{F}_{\mathrm{Mmax}}$.

The required current speed $\omega_{M}\left(n_{M}\right)$ or $v_{M}$ and required current load $M_{M}$ or $F_{M}$ of the driven machine are an effect of its work cycle and the work task. The current driven machine speed and load values are independent of the type and structure of that machine driving system control (e.g. an electrical or hydrostatic system).

The current speed and current load of a hydrostatic system driven machine have a direct or indirect impact on the mechanical, volumetric and pressure losses in the hydraulic motor, pump and other system elements, a system with determined motor speed control structure. The losses are also an effect of the viscosity of the used working liquid (hydraulic oil).

The current speed $\omega_{M}\left(n_{M}\right)$ or $v_{M}$ and current load $M_{M}$ or $F_{M}$ of the driven machine influence, in consequence, the current hydraulic motor absorption capacity $Q_{M}$ and pressure decrease $\Delta \mathbf{p}_{M}$ and also (depending on the used motor speed control structure) the current pump capacity $Q_{P}$ and discharge pressure $p_{P 2}$.

If in effect of the increasing, required by the driven machine (device) hydraulic motor speed $\omega_{M}\left(n_{M}\right)$ or $v_{M}$, as well as in effect of the increasing, required by the driven machine motor load $\mathrm{M}_{\mathrm{M}}$ or $\mathrm{F}_{\mathrm{M}}$, and also in effect of the mechanical, volumetric and pressure losses of the hydrostatic drive system elements, the maximum drive system capacity (determined by the maximum pump capacity $\mathrm{Q}_{\mathrm{P} \max }$ or maximum pump discharge conduit pressure $p_{\mathrm{P} 2 \max }$ limited to the system nominal pressure $\mathrm{p}_{\mathrm{n}}$ ) is fully used, then further increase of $\omega_{M}\left(n_{M}\right)$ or $v_{M}$ as well as $\mathrm{M}_{\mathrm{M}}$ or $\mathrm{F}_{\mathrm{M}}$ will not be possible.

Maximum pump capacity $\mathrm{Q}_{\mathrm{P}_{\max }}$ is smaller than its theoretical capacity $\mathrm{Q}_{\mathrm{Pt}_{\mathrm{t}}}$. The pump theoretical capacity $\mathrm{Q}_{\mathrm{Pt}}$ is a product of the theoretical capacity $\mathrm{q}_{\mathrm{Pt}}$ per one pump shaft revolution and the no-load pump shaft speed $\mathrm{n}_{\mathrm{P} 0}$. The pump $\mathrm{Q}_{\mathrm{Pmax}}$ capacity, however, results from the loaded pump speed $n_{p}$, lower than the speed $\mathrm{n}_{\mathrm{P} 0}$, and from volumetric losses in the pump.

The system nominal pressure $\mathrm{p}_{\mathrm{n}}$ is a maximum permissible continuous operation pressure $\mathrm{p}_{\mathrm{P} 2 \max }$ determined in the pump discharge.

The maximum speed values $\omega_{M \max }\left(n_{M \max }\right)$ or $v_{M \max }$ as well as the maximum load values $M_{M \max }$ or $F_{M \max }$ of the hydraulic motor used in a hydrostatic drive system are limited by the maximum pump capacity $Q_{P \max }$ or by the system (pump) nominal pressure $\mathbf{p}_{\mathrm{n}}$ and also by the corresponding mechanical, volumetric and pressure losses in the remaining system elements, the losses being also an effect of viscosity of the working liquid used. Therefore, the $\omega_{M \max }\left(\mathbf{n}_{M \max }\right)$ or $\mathbf{v}_{\mathrm{Mmax}}$, $\mathbf{M}_{M \max }$ or $\mathbf{F}_{\text {Mmax }}$ values are dependent variables.

The current mechanical operating parameters of the hydraulic motor used in a hydrostatic drive system (current motor speed $\omega_{M}\left(n_{M}\right)$ or $\mathrm{v}_{M}$ and current motor load $\mathrm{M}_{M}$ or $\left.\mathrm{F}_{\mathrm{M}}\right)$ are independent values in the motor, deciding of the motor losses and of the hydraulic parameters (the current motor absorbing capacity $\mathrm{Q}_{\mathrm{M}}$ and current pressure decrease $\Delta \mathrm{p}_{\mathrm{M}}$ also depending on the motor mechanical, volumetric and pressure losses). The current motor absorbing capacity $Q_{M}$ and current pressure decrease $\Delta \mathbf{p}_{\mathrm{M}}$ are dependent variables in the motor.

In the hydraulic motor (hydrostatic drive system) operating field $\left(0 \leq \omega_{\mathrm{M}}\left(\mathrm{n}_{\mathrm{M}}\right)<\omega_{\mathrm{M} \max }\left(\mathrm{n}_{\mathrm{M} \max }\right), 0 \leq \mathrm{M}_{\mathrm{M}}<\mathrm{M}_{\mathrm{M} \max }\right)$ or $\left(0 \leq \mathrm{v}_{\mathrm{M}}<\right.$ $\left.<\mathrm{v}_{\mathrm{Mmax}}, 0 \leq \mathrm{F}_{\mathrm{M}}<\mathrm{F}_{\mathrm{Mmax}}\right)$, the pressure and flow intensities in the system and also the energy losses in the motor, in the pump and in the whole system, power of energy losses and energy efficiencies of the system elements should be considered the functions of the current speed $\omega_{\mathrm{M}}\left(\mathrm{n}_{\mathrm{M}}\right)$ or $\mathrm{v}_{\mathrm{M}}$ and the current load $\mathrm{M}_{\mathrm{M}}$ or $\mathrm{F}_{\mathrm{M}}$ required by the system driven machine (device). Also the torque $M_{P}$ that the pump loads the driving (electric or internal combustion) motor and the speed $n_{p}$ that the motor drives the pump with should be considered the functions of the current speed and the current load required by the system driven machine.

The decrease of speed $n_{P}$ that the electric or internal combustion motor drives the pump with is connected with the increase of torque $\mathrm{M}_{\mathrm{P}}$ that the pump loads the motor with. The decrease of speed depends on the operating characteristics of the motor, which is not a component of the hydrostatic drive system. Therefore, the pump driving speed $\mathbf{n}_{\mathrm{P}}$ should be treated as a parameter independent of the hydrostatic system (of the pump).

\section{NON-DIMENTIONAL COEFFICIENTS OF THE DISPLACEMENT MOTOR PARAMETERS, COEFFICIENTS OF ENERGY LOSSES IN THE HYDROSTATIC DRIVE ELEMENTS}

The energy efficiency of the hydrostatic drive system and its elements is described by mathematical models as functions of the hydraulic motor (hydrostatic drive system) speed coefficient $\bar{\omega}_{\mathrm{M}}$ and load coefficient $\overline{\mathrm{M}}_{\mathrm{M}}$.

The current angular speed $\omega_{M}$ (rotational speed $\mathbf{n}_{M}$ ) required of a rotational motor or the linear speed $v_{M}$ required of a linear motor, operating in a hydrostatic drive system, are replaced in the energy efficiency mathematical 
models by the motor speed non-dimensional coefficient $\bar{\omega}_{\mathbf{M}}$ :

$$
\bar{\omega}_{\mathrm{M}}=\frac{\omega_{\mathrm{M}}}{\omega_{\mathrm{Mt}}}=\frac{\mathrm{n}_{\mathrm{M}}}{\mathrm{n}_{\mathrm{Mt}}}=\frac{\omega_{\mathrm{M}} \mathrm{q}_{\mathrm{Mt}}}{2 \Pi \mathrm{Q}_{\mathrm{Pt}}}=\frac{\mathrm{n}_{\mathrm{M}} \mathrm{q}_{\mathrm{Mt}}}{\mathrm{Q}_{\mathrm{Pt}}}
$$

or

$$
\bar{\omega}_{\mathrm{M}}=\frac{\mathrm{v}_{\mathrm{M}}}{\mathrm{v}_{\mathrm{Mt}}}=\frac{\mathrm{v}_{\mathrm{M}} \mathrm{S}_{\mathrm{M} 1}}{\mathrm{Q}_{\mathrm{Pt}}}
$$

The rotational hydraulic motor speed coefficient $\bar{\omega}_{M}$ is a ratio of the current angular speed $\omega_{M}$ (rotational speed $n_{M}$ ), required of the motor by driven machine, to

$$
\begin{aligned}
& \text { theoretical angular speed } \omega_{\mathrm{Mt}}=\frac{2 \Pi \mathrm{Q}_{\mathrm{Pt}}}{\mathrm{q}_{\mathrm{Mt}}}, \\
& \text { (theoretical rotational speed } \mathrm{n}_{\mathrm{Mt}}=\frac{\mathrm{Q}_{\mathrm{Pt}}}{\mathrm{q}_{\mathrm{Mt}}} \text {, }
\end{aligned}
$$

which would correspond with the theoretical capacity $\mathrm{Q}_{\mathrm{Pt}}$ of the motor driving pump and with the theoretical motor absorbing capacity $\mathrm{q}_{\mathrm{Mt}}$ per one shaft revolution. The speed $\omega_{\mathrm{Mt}}\left(\mathrm{n}_{\mathrm{Mt}}\right)$ would be achievable on the condition, that there are no volumetric losses in the hydrostatic drive system (including the pump and the hydraulic motor) and the pump is driven by an (electric or internal combustion) motor operating with constant rotational speed $n_{P}=n_{P 0}$ independent of its load.

The theoretical angular speed $\omega_{\mathrm{Mt}}$ (rotational speed $\left.\mathbf{n}_{\mathrm{Mt}}\right)$ of a rotational motor is treated as a constant reference value for the motor current angular speed $\omega_{M}$ (rotational speed $n_{M}$ ).

The linear hydraulic motor speed coefficient $\bar{\omega}_{M}$ is a ratio of the current linear speed $\mathrm{v}_{\mathrm{M}}$, required of the motor by driven machine, to

$$
\text { theoretical linear speed } v_{M t}=\frac{Q_{P t}}{S_{M 1}},
$$

which would correspond with the theoretical capacity $\mathrm{Q}_{\mathrm{Pt}}$ of the motor driving pump and with effective area $\mathrm{S}_{\mathrm{M} 1}$ of the motor piston in the inlet chamber. The speed $\mathrm{v}_{\mathrm{Mt}}$ would be achievable on the condition, that there are no volumetric losses in the hydrostatic drive system (including the pump and the hydraulic motor) and the pump is driven by an (electric or internal combustion) motor operating with constant rotational speed $\mathrm{n}_{\mathrm{P}}=\mathrm{n}_{\mathrm{P} 0}$ independent of its load.

The theoretical linear speed $v_{\mathrm{Mt}}$ of a linear motor is treated as a constant reference value for the current motor linear speed $\mathrm{v}_{\mathrm{M}}$.

The current torque $M_{M}$ required of a rotational motor or current force $F_{M}$ required of a linear motor, operating in a hydrostatic drive system, are replaced by the motor load non-dimensional coefficient $\overline{\mathbf{M}}_{\mathbf{M}}$ :

or

$$
\overline{\mathrm{M}}_{\mathrm{M}}=\frac{\mathrm{M}_{\mathrm{M}}}{\mathrm{M}_{\mathrm{Mt}}}=\frac{2 \Pi \mathrm{M}_{\mathrm{M}}}{\mathrm{q}_{\mathrm{Mt}} \mathrm{p}_{\mathrm{n}}}
$$

$$
\overline{\mathrm{M}}_{\mathrm{M}}=\frac{\mathrm{F}_{\mathrm{M}}}{\mathrm{F}_{\mathrm{Mt}}}=\frac{\mathrm{F}_{\mathrm{M}}}{\mathrm{S}_{\mathrm{M} 1} \mathrm{p}_{\mathrm{n}}}
$$

The rotational hydraulic motor load coefficient $\overline{\mathbf{M}}_{M}$ is a ratio of the current torque $\mathrm{M}_{\mathrm{M}}$, required of the motor by driven machine, to

$$
\text { theoretical torque } \mathrm{M}_{\mathrm{Mt}}=\frac{\mathrm{q}_{\mathrm{Mt}} \mathrm{p}_{\mathrm{n}}}{2 \Pi}
$$

which would correspond with the theoretical absorbing capacity $\mathrm{q}_{\mathrm{Mt}}$ per one motor shaft revolution and with the hydrostatic system nominal pressure $\mathrm{p}_{\mathrm{n}}$. The torque $\mathrm{M}_{\mathrm{Mt}}$ would be achievable on the condition that there are no mechanical or pressure losses in the hydraulic motor and in the remaining system elements (except the pump) and the pressure $p_{\text {P2max }}$ in the pump discharge conduit is equal to the system nominal pressure $p_{n}$

The rotational motor theoretical torque $\mathrm{M}_{\mathrm{Mt}}$ is treated as a constant reference value for the current motor torque $M_{M}$.

The linear hydraulic motor load coefficient $\overline{\mathbf{M}}_{M}$ is a ratio of the current force $\mathrm{F}_{\mathrm{M}}$, required of the motor by driven machine, to

$$
\text { theoretical force } \mathrm{F}_{\mathrm{Mt}}=\mathrm{S}_{\mathrm{M} 1} \mathrm{p}_{\mathrm{n}} \text {, }
$$

which would correspond with the effective area $\mathrm{S}_{\mathrm{M} 1}$ of the motor piston in its inlet chamber and with the system nominal pressure $\mathrm{p}_{\mathrm{n}}$. The force $\mathrm{F}_{\mathrm{Mt}}$ would be achievable on the condition that there are no mechanical or pressure losses in the hydraulic motor and in the remaining system elements (except the pump) and the pressure $\mathrm{p}_{\mathrm{P} 2 \max }$ in the pump discharge conduit is equal to the system nominal pressure $\mathrm{p}_{\mathrm{n}}$.

The linear motor theoretical force $F_{M t}$ is treated as a constant reference value for the current motor force $F_{M}$.

The mechanical, volumetric and pressure losses in a hydraulic motor, pump and in the remaining hydrostatic drive system elements are described in the mathematical models of the losses, power of losses and energy efficiency by the coefficients $\mathbf{k}_{\mathbf{i}}$ - relations to the values connected with the values of the hydrostatic drive system characteristic parameters:

- theoretical capacity $\mathrm{q}_{\mathrm{Pt}}$ per one pump shaft revolution,

- theoretical absorbing capacity $\mathrm{q}_{\mathrm{Mt}}$ per one rotational hydraulic motor revolution or effective piston area $\mathrm{S}_{\mathrm{M} 1}$ in the linear motor inlet chamber,

- theoretical pump capacity $\mathrm{Q}_{\mathrm{Pt}}$,

- system nominal pressure $\mathrm{p}_{\mathrm{n}}$.

The basis of energy evaluation of the particular design solutions and size of the volumetric machines is a catalogue of the coefficients $k_{i}$ of energy losses in various types of pumps and hydraulic motors used in the hydrostatic drive systems, operating with different levels of pump theoretical capacity $Q_{P t}$ and system nominal pressure $p_{n}$, with the working liquid reference viscosity $v_{n}$.

\section{THE MOTOR OPERATING FIELD IN A DRIVE SYSTEM}

Figure 1 presents the operating field of a rotational or linear displacement motor in a hydrostatic drive system. The operating field is determined in the plane of motor mechanical parameters, i.e. speed coefficient $\bar{\omega}_{M}$ and load coefficient $\bar{M}_{M}$, independent of the motor and of the system.

The limit values $\bar{\omega}_{M \max }=\mathrm{f}\left(\overline{\mathrm{M}}_{\mathrm{M}}\right)$ or $\overline{\mathrm{M}}_{\mathrm{Mmax}}=\mathrm{f}\left(\bar{\omega}_{\mathrm{M}}\right)$ of the hydraulic motor operating field are determined by the maximum motor feed capability in the hydrostatic drive system. The values $\bar{\omega}_{M \max }$ and $\overline{\mathbf{M}}_{M \max }$ are dependent on the motor and on the system losses.

The maximum motor absorbing capacity $\mathbf{Q}_{\mathrm{M} \max }$, achieved in the system by the applied motor speed control structure, should be equal or close to the instantaneous maximum pump capacity $\mathbf{Q}_{\mathrm{Pmax}}$ (resulting from the theoretical capacity $\mathrm{Q}_{\mathrm{Pt}}$, decrease of the pump shaft rotational speed $\mathrm{n}_{\mathrm{P}}$ and the intensity of pump volumetric losses $\mathrm{Q}_{\mathrm{Pv}_{\mathrm{v}}}$ ).

The maximum possible motor pressure decrease $\Delta \mathbf{p}_{\mathrm{Mmax}}$ should be equal or close to the system nominal pressure $p_{n}$ determined in the pump discharge conduit, reduced by the pressure losses $\Delta \mathbf{p}_{\mathrm{C}}$ in the system conduit. (In the motor series 


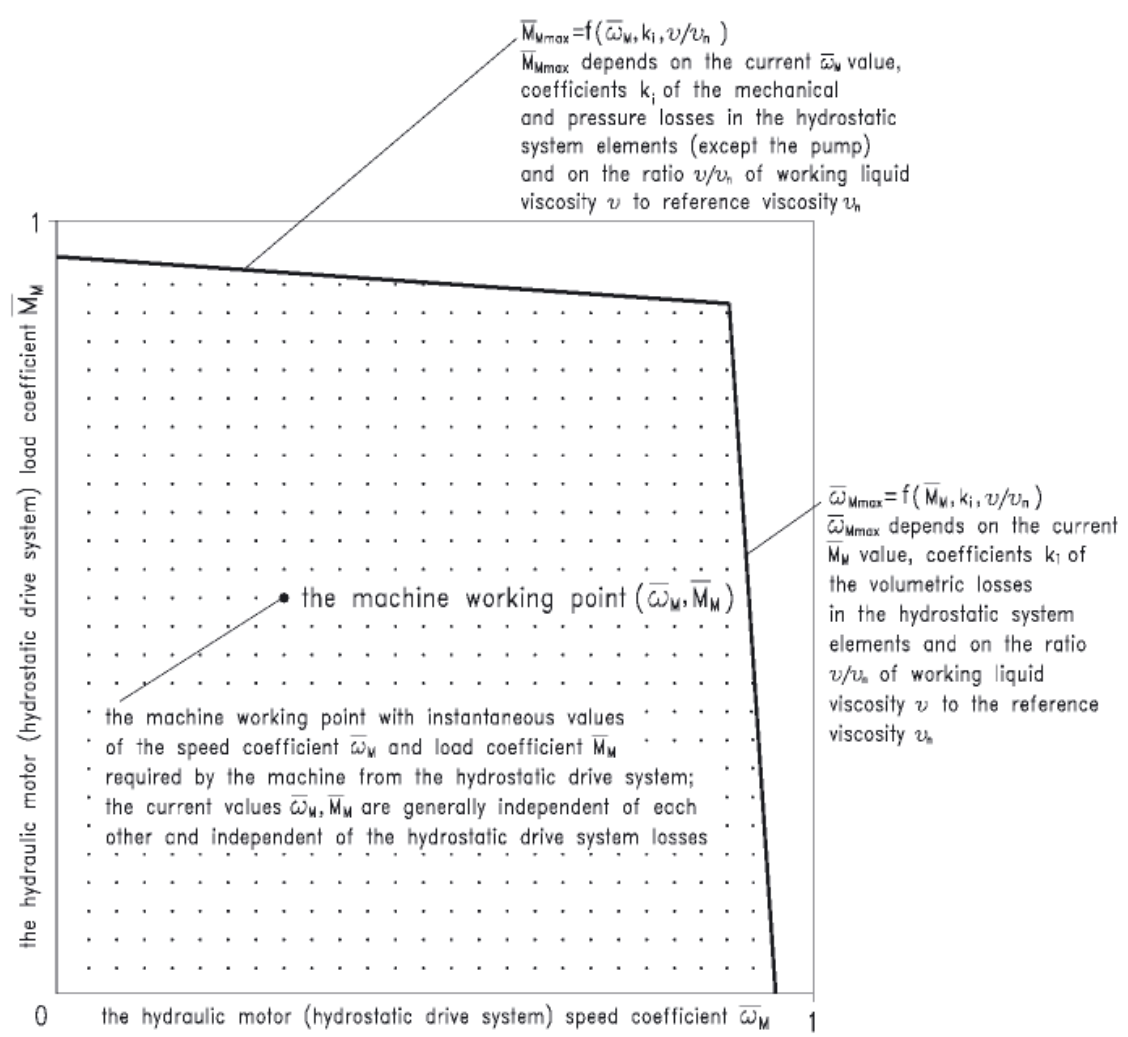

Fig. 1. The range of motor speed coefficient $\bar{\omega}_{M}$ and load coefficient $\bar{M}_{M}\left(0 \leq \bar{\omega}_{M}<\bar{\omega}_{M \max }, 0 \leq \bar{M}_{M}<\bar{M}_{M \text { max }}\right)$ in a hydrostatic drive system

throttling speed control structure, the maximum slot area of the throttling valve, proportional directional valve or servo-valve should allow to minimize the pressure decrease $\Delta \mathrm{p}_{\mathrm{DE} \mid \mathrm{Q}_{\mathrm{Mmax}}}$ with the set $\left.\mathrm{Q}_{\mathrm{Mmax}} \approx \mathrm{Q}_{\mathrm{Pmax}}\right)$.

Therefore the limit values $\bar{\omega}_{\text {Mmax }}$ of the hydraulic motor speed coefficient are a function of the current motor load coefficient $\overline{\mathrm{M}}_{\mathrm{M}}$, coefficients $\mathrm{k}_{\mathrm{i}}$ of the volumetric losses in the hydrostatic system elements (including coefficient $\mathrm{k}_{2}$ of the pump shaft rotational speed decrease $\Delta \mathrm{n}_{\mathrm{P}}$ ) and a function of the ratio $v / v_{n}$ of working liquid viscosity $v$ to the reference viscosity $v_{\mathrm{n}}$

On the other hand, the limit values $\overline{\mathrm{M}}_{\mathrm{Mmax}}$ of the hydraulic motor load coefficient are a function of the current motor speed coefficient $\bar{\omega}_{\mathrm{M}}$, coefficients $\mathrm{k}_{\mathrm{i}}$ of the mechanical and pressure losses in hydrostatic system elements and a function of the ratio $v / v_{n}$ of working liquid viscosity $v$ to the reference viscosity $v_{n}$

\section{DIRECTION OF POWER INCREASE IN A DRIVE SYSTEM}

The Sankey diagram is the fundamental cause of the incorrect evaluation of losses in a drive system.

The Sankey diagram connected with a drive system suggests an evaluation defining the output power of the system as a difference between the system input power and sum of the powers of losses occurring in the system. Therefore the energy losses in the system are evaluated as a function of parameters describing the input power.

In accordance with the proposed by the author diagram of power increase in a drive system opposite to the direction of power flow, the system input power is a sum of the system output power and powers of losses occurring in the system. The energy losses in the system are evaluated as a function of parameters describing the system output power.

Full picture of the energy losses in a drive system is a picture of power of energy losses in the system elements.
Shaft power of the hydrostatic system feeding pump is equal to the sum of hydraulic motor shaft (or piston rod) power and powers of individual losses in the power flowing from the pump shaft to the hydraulic motor shaft (or piston rod).

The quantity of power increases, in order to overcome the power of energy losses, in the opposite direction to the direction of power flow. Therefore, the image of power of energy losses in the system should be constructed in the direction from the hydraulic rotational motor shaft or from linear motor piston rod towards the system feeding pump shaft.

Power of the hydraulic motor, pump and of other system element losses (mechanical, volumetric, pressure losses) should be determined as functions of the parameters independent of those losses and influencing directly those losses.

Powers of energy losses in the system elements and also power of those elements must be precisely defined.

\section{DIAGRAM OF POWER INCREASE IN A ROTATIONAL DISPLACEMENT HYDRAULIC MOTOR, REPLACING THE SANKEY DIAGRAM}

Figure 2 illustrates the diagram, proposed by the Author, of power increase in a rotational hydraulic motor opposite to the direction of power flow, replacing the Sankey diagram of power decrease in the direction of power flow.

The power $\mathrm{P}_{\mathrm{Mc}}$ consumed by the hydraulic motor is a sum of motor shaft useful power $\mathrm{P}_{\mathrm{Mu}}$ and powers of three different energy losses in the motor. The losses occur in series increasing power in the opposite direction to the direction of power flow. In effect, the power in the motor increases from the shaft useful power $\mathrm{P}_{\mathrm{Mu}}$ to the working liquid power $\mathrm{P}_{\mathrm{Mc}}$ consumed by the motor:

$$
\mathrm{P}_{\mathrm{Mc}}=\mathrm{P}_{\mathrm{Mu}}+\Delta \mathrm{P}_{\mathrm{Mm}}+\Delta \mathrm{P}_{\mathrm{Mv}}+\Delta \mathrm{P}_{\mathrm{Mp}}
$$



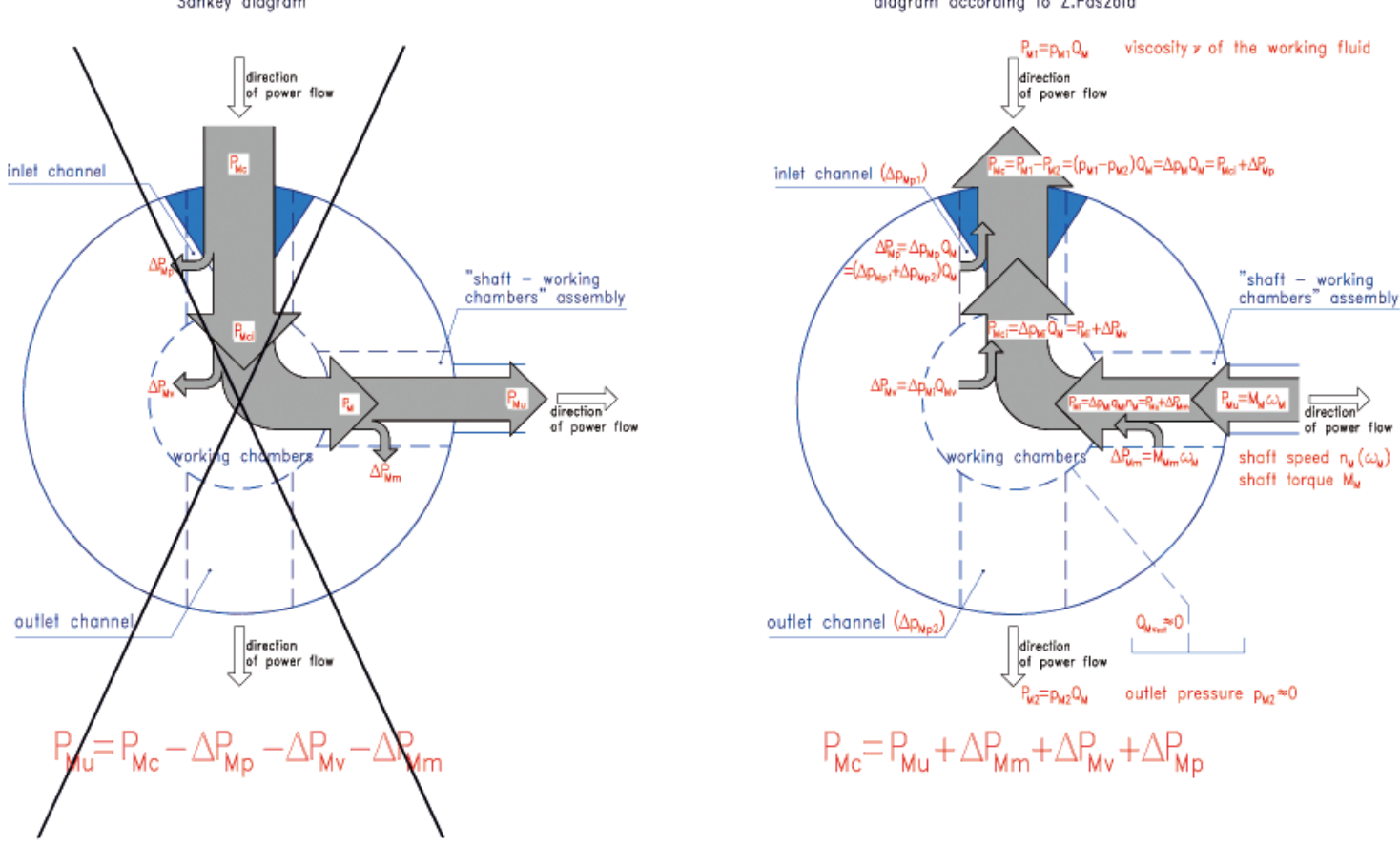

Fig. 2. Diagram of power increase in a rotational displacement hydraulic motor, opposite to the direction of power flow, replacing the Sankey diagram of power decrease in the direction of power flow (example of motor with theoretical (constant) capacity $q_{M t}\left(V_{M t}\right)$ per one shaft revolution)

Power increases from the motor useful power $P_{M u}$ required on the motor shaft by the driven machine (device) to power $P_{\text {consumed }}$ and required by the motor of the working liquid.

The increase of power is an effect of the powers of losses in the motor: power $\Delta P_{M m}$ of mechanical losses in the "shaft - working chambers" assembly, power $\Delta P_{M v}$ of volumetric losses in the working chambers and power $\Delta P_{M p}$ of pressure losses in the channels.

Powers $\Delta P_{M m}, \Delta P_{M v}$ and $\Delta P_{M p}$ of the losses are functions of the output parameters of the motor assembly where the losses occur and diversified functions of the working liquid viscosity v: power $\Delta P_{M m}$ of mechanical losses is a function of torque $M_{M}$ and shaft speed $n_{M}\left(\omega_{M}\right)$ required of the motor by the driven machine (device) and a function of the working liquid viscosity $v$, power $\Delta P_{u v}$ of volumetric losses is a function of the pressure decrease $\Delta p_{M i}$ indicated in working chambers (of torque $M_{M i}$ indicated in the chambers) and of the shaft rotational speed $n_{M}$ as well as a function of the working liquid viscosity $v$, power $\Delta P_{M p}$ of pressure losses is a function of motor capacity $Q_{M}$ and of the working liquid viscosity $v$.

Power $P_{M i}$ indicated in the working chambers: $P_{M i}=P_{M u}+\Delta P_{M m}$, power $P_{M c i}$ of the working liquid consumed in the working chambers. $P_{M c i}=P_{M u}+\Delta P_{M m}+\Delta P_{M v}$ power $P_{M c}$ of the working liquid consumed by the motor:

$$
P_{M c}=P_{M u}+\Delta P_{M m}+\Delta P_{M v}+\Delta P_{M p} \text {. }
$$

The proposed diagram replaces the Sankey diagram of distribution of power in hydraulic motor causing incorrect loss evaluation during the hydraulic motor energy investigations.

Mechanical losses (and power $\Delta \mathrm{P}_{\mathrm{Mm}}$ of mechanical losses) occur in the ,shaft - working chambers" assembly.

Volumetric losses (and power $\Delta \mathrm{P}_{\mathrm{Mv}}$ of volumetric losses) occur in the working chambers.

Pressure losses (and power $\Delta \mathrm{P}_{\mathrm{Mp}}$ of pressure losses) occur in the channels.

\section{COMPLEX DEPENDENCE OF ENERGY LOSSES IN A ROTATIONAL DIPLACEMEMENT HYDRAULIC MOTOR ON THE SHAFT SPEED, ON THE SHAFT TORQUE, ON THE CAPACITY PER ONE SHAFT REVOLUTION AND ON THE WORKING LIQUID VISCOSITY}

There exists a direct dependence of the torque $\mathrm{M}_{\mathrm{Mm}}$ of mechanical losses in the „shaft - working chambers” assembly on the torque $\mathrm{M}_{\mathrm{M}}$, on the motor shaft rotational speed $\mathrm{n}_{\mathrm{M}}$, on the capacity $\mathrm{q}_{\mathrm{Mt}}\left(\right.$ or $\mathrm{q}_{\mathrm{Mgv}}$ ) per one shaft revolution as well as on the working liquid viscosity $v$.

There is a complex dependence of the intensity $\mathrm{Q}_{\mathrm{Mv}}$ of volumetric losses in the working chambers on the shaft loading torque $\mathrm{M}_{\mathrm{M}}$ and on the torque $\mathrm{M}_{\mathrm{Mm}}$ of mechanical losses in the "shaft - working chambers" assembly (decrease $\Delta \mathrm{p}_{\mathrm{Mi}}$ of pressure indicated in the working chambers depends on $\mathrm{M}_{\mathrm{M}}$ and $\mathrm{M}_{\mathrm{Mm}}$, on $\mathrm{q}_{\mathrm{Mt}}\left(\right.$ or $\mathrm{q}_{\mathrm{Mgv}}$ ) and has direct impact on $\mathrm{Q}_{\mathrm{Mv}}$ ) and also on the shaft speed $\mathrm{n}_{\mathrm{M}}$ (influencing in a diversified way the torque
$\mathrm{M}_{\mathrm{Mm}}$ of mechanical losses and intensity $\mathrm{Q}_{\mathrm{Mv}}$ of volumetric losses). The intensity $\mathrm{Q}_{\mathrm{Mv}}$ of volumetric losses depends on a diversified impact of the working liquid viscosity $v$ : indirectly by impact of $v$ on the torque $\mathrm{M}_{\mathrm{Mm}}$ of mechanical losses in the „shaft - working chambers" assembly and directly by impact of $v$ on the intensity $\mathrm{Q}_{\mathrm{Mv}}$ of losses in the working chambers.

It can be said, that it is a complex dependence of pressure losses $\Delta \mathrm{p}_{\mathrm{Mp}}$ in the channels on the shaft rotational speed $\mathrm{n}_{\mathrm{M}}$, on the capacity $\mathrm{q}_{\mathrm{Mt}}$ ( or $\mathrm{q}_{\mathrm{Mgv}}$ ) per one shaft revolution and on intensity $\mathrm{Q}_{\mathrm{Mv}}$ of volumetric losses in the working chambers. The intensity $\mathrm{Q}_{\mathrm{Mv}}$ of volumetric losses influences the motor capacity $\mathrm{Q}_{\mathrm{M}}$ and at the same time $\mathrm{Q}_{\mathrm{Mv}}$ depends in a complex way on the shaft loading torque $\mathrm{M}_{\mathrm{M}}$ and on the torque $\mathrm{M}_{\mathrm{Mm}}$ of mechanical losses in the "shaft - working chambers" assembly. Pressure losses $\Delta \mathrm{p}_{\mathrm{Mp}}$ in the motor channels are also dependent on the diversified impact of the working liquid viscosity $v$ : indirectly by impact of $v$ on the torque $\mathrm{M}_{\mathrm{Mm}}$ of mechanical losses in the „shaft - working chambers" assembly and by impact of $v$ on the intensity $\mathrm{Q}_{\mathrm{Mv}}$ of volumetric losses in the working chambers and directly by impact of $v$ on the losses $\Delta \mathrm{p}_{\mathrm{Mp}}$ of pressure in the channels.

Contrary to the commonly used, both by manufacturers and researchers, methods of evaluation of the rotational hydraulic motor losses, it is unacceptable to create a ,sum" of the torque $\mathrm{M}_{\mathrm{Mm}}$ of mechanical losses in the ,shaft - working chambers" assembly and the ,torque" of pressure losses $\Delta \mathrm{p}_{\mathrm{Mp}}$ in the motor channels, and also such a ,sum" must not be evaluated as 
directly dependent on the same chosen parameters, because those losses are of different character and depend on different parameters:

$$
\begin{gathered}
\mathrm{M}_{\mathrm{Mm}}=\mathrm{f}\left(\mathrm{M}_{\mathrm{M}}, \mathrm{n}_{\mathrm{M}}, \mathrm{q}_{\mathrm{Mt}}\left(\mathrm{q}_{\mathrm{Mqv}}\right), \mathrm{v}\right) \\
\Delta \mathrm{p}_{\mathrm{Mp}}=\mathrm{f}\left(\mathrm{Q}_{\mathrm{M}}, v\right)
\end{gathered}
$$

The impact of hydraulic oil viscosity $v$ on the energy losses in a hydraulic motor, i.e. on:

- torque $\mathbf{M}_{\mathrm{Mm}}$ of mechanical losses in the ,shaft - working chambers" assembly,

- intensity $Q_{M v}$ of volumetric losses in the working chambers,

- pressure losses $\Delta \mathbf{p}_{\mathrm{Mp}}$ in the channels,

is diversified.

Dependence of the motor losses on the hydraulic oil viscosity $v$ should be presented in expressions describing also the dependence of those losses on other parameters which influence them directly:

$$
\begin{gathered}
\mathrm{M}_{\mathrm{Mm}}=\mathrm{f}\left(\mathrm{M}_{\mathrm{M}}, \mathrm{n}_{\mathrm{M}}, \mathrm{q}_{\mathrm{Mt}}\left(\mathrm{q}_{\mathrm{Mqv}}\right), v\right) \\
\mathrm{Q}_{\mathrm{Mv}}=\mathrm{f}\left(\Delta \mathrm{p}_{\mathrm{Mi}}, \mathrm{n}_{\mathrm{M}}, v\right) \\
\Delta \mathrm{p}_{\mathrm{Mp}}=\mathrm{f}\left(\mathrm{Q}_{\mathrm{M}}, v\right)
\end{gathered}
$$

The motor overall efficiency $\boldsymbol{\eta}_{M}$, as a function of $\mathrm{M}_{\mathrm{M}}, \mathrm{n}_{\mathrm{M}}, \mathrm{q}_{\mathrm{Mt}}\left(\mathrm{q}_{\mathrm{Mqv}}\right)$ and $\mathrm{v}$, is a product of $\eta_{\mathrm{Mm}}, \eta_{\mathrm{Mv}}$ and $\eta_{\mathrm{Mp}}$ efficiencies:

$$
\begin{gathered}
\eta_{M}=f\left(M_{M}, n_{M}, q_{M t}\left(q_{M q v}\right), v\right)= \\
=\frac{P_{M u}}{P_{M c}}=\frac{M_{M} \omega_{M}}{\Delta p_{M} Q_{M}}=\frac{2 \Pi M_{M} n_{M}}{\Delta p_{M} Q_{M}}= \\
=\eta_{M m} \eta_{M v} \eta_{M p}
\end{gathered}
$$

where:

$P_{\mathrm{Mu}}$ is the motor useful power,

$P_{M c}$ is the motor consumed power.

Each of the three efficiencies, as a factor in the product describing the overall efficiency, is evaluated as a function of parameters directly influencing the respective losses and a function of parameter to which the losses are ,added":

- motor mechanical efficiency $\eta_{M m}$ :

$$
\begin{gathered}
\eta_{M m}=\frac{P_{M u}}{P_{M i}}=\frac{M_{M} \omega_{M}}{\left(M_{M}+M_{M m}\right) \omega_{M}}= \\
=\frac{2 \Pi M_{M} n_{M}}{2 \Pi\left(M_{M}+M_{M m}\right) n_{M}}= \\
=\frac{M_{M}}{M_{M}+M_{M m}}=f\left(M_{M}, n_{M}, q_{M t}\left(q_{M g v}\right), v\right)
\end{gathered}
$$

where:

$\mathbf{P}_{\mathrm{Mi}}$ is the power indicated in the motor working chambers:

$$
\begin{gathered}
\mathrm{P}_{\mathrm{Mi}}=\Delta \mathrm{p}_{\mathrm{Mi}} \mathrm{q}_{\mathrm{Mt}}\left(\mathrm{q}_{\mathrm{Mgv}}\right) \mathrm{n}_{\mathrm{M}}= \\
=\left(\mathrm{M}_{\mathrm{M}}+\mathrm{M}_{\mathrm{Mm}}\right) \omega_{\mathrm{M}}=2 \Pi\left(\mathrm{M}_{\mathrm{M}}+\mathrm{M}_{\mathrm{Mm}}\right) \mathrm{n}_{\mathrm{M}}
\end{gathered}
$$

- motor volumetric efficiency $\eta_{\mathrm{Mv}}$ :

$$
\begin{gathered}
\eta_{M v}=\frac{P_{M i}}{P_{M c i}}=\frac{\Delta p_{M i} q_{M t}\left(q_{M g v}\right) n_{M}}{\Delta p_{M i}\left(q_{M t}\left(q_{M g v}\right) n_{M}+Q_{M v}\right)}= \\
=\frac{\Delta p_{M i} q_{M t}\left(q_{M g v}\right) n_{M}}{\Delta p_{M i} Q_{M}}=\frac{q_{M t}\left(q_{M g v}\right) n_{M}}{q_{M t}\left(q_{M g v}\right) n_{M}+Q_{M v}} \\
=\frac{q_{M t}\left(q_{M g v}\right) n_{M}}{Q_{M}}=f\left(\Delta p_{M i}, q_{M t}\left(q_{M g v}\right), n_{M}, v\right)
\end{gathered}
$$

where $\mathbf{P}_{\text {Mci }}$ is the power consumed in the motor working chambers:

$$
\mathrm{P}_{\mathrm{Mci}}=\Delta \mathrm{p}_{\mathrm{Mi}}\left(\mathrm{q}_{\mathrm{Mt}}\left(\mathrm{q}_{\mathrm{Mgv}}\right) \mathrm{n}_{\mathrm{M}}+\mathrm{Q}_{\mathrm{Mv}}\right)=\Delta \mathrm{p}_{\mathrm{Mi}} \mathrm{Q}_{\mathrm{M}}
$$

- motor pressure efficiency $\eta_{M p}$ :

$$
\begin{aligned}
\eta_{M p}=\frac{P_{M c i}}{P_{M c}}= & \frac{\Delta p_{M i}\left(q_{M t}\left(q_{M g v}\right) n_{M}+Q_{M v}\right)}{\left(\Delta p_{M i}+\Delta p_{M p}\right)\left(q_{M t}\left(q_{M g v}\right) n_{M}+Q_{M v}\right)}= \\
= & \frac{\Delta p_{M i} Q_{M}}{\Delta p_{M} Q_{M}}=\frac{\Delta p_{M i}}{\Delta p_{M i}+\Delta p_{M p}} \\
& =\frac{\Delta p_{M i}}{\Delta p_{M}}=f\left(\Delta p_{M i}, Q_{M}, v\right)
\end{aligned}
$$

In order to present the motor volumetric efficiency $\eta_{\mathrm{Mv}}$ as a factor in the $\eta_{\mathrm{Mm}} \eta_{\mathrm{Mv}} \eta_{\mathrm{Mp}}$ product describing $\eta_{\mathrm{M}}$, i.e. to present $\eta_{\mathrm{Mv}}$ as a complex dependence on the $\left(\mathrm{M}_{\mathrm{M}}, \mathrm{n}_{\mathrm{M}}, \mathrm{q}_{\mathrm{Mt}}\left(\mathrm{q}_{\mathrm{Mgv}}\right), v\right)$ parameters describing $\eta_{\mathrm{M}}$ and dependent on the mechanical losses, the intensity $\mathrm{Q}_{\mathrm{Mv}}=\mathrm{f}\left(\Delta \mathrm{p}_{\mathrm{Mi}}, \mathrm{n}_{\mathrm{M}}, \mathrm{q}_{\mathrm{Mt}}\left(\mathrm{q}_{\mathrm{Mgv}}\right), v\right)$ of volumetric losses in the working chambers should be determined with

$$
\Delta \mathrm{p}_{\mathrm{Mi}}=\frac{2 \Pi\left(\mathrm{M}_{\mathrm{M}}+\mathrm{M}_{\mathrm{Mm}}\right)}{\mathrm{q}_{\mathrm{Mt}}\left(\mathrm{q}_{\mathrm{Mgv}}\right)}
$$

and with torque $\mathrm{M}_{\mathrm{Mm}}$ of mechanical losses in the ,shaft - working chambers" assembly as an $\mathrm{M}_{\mathrm{Mm}}=\mathrm{f}\left(\mathrm{M}_{\mathrm{M}}, \mathrm{n}_{\mathrm{M}}\right.$, $\left.\mathrm{q}_{\mathrm{Mt}}\left(\mathrm{q}_{\mathrm{Mgv}}\right), v\right)$ function.

In order to present the motor pressure efficiency $\eta_{\mathrm{Mp}}$ as a factor in the $\eta_{M m} \eta_{M v} \eta_{M p}$ product describing $\eta_{M}$, i.e. to present $\eta_{M p}$ as a complex dependence on the $\left(\mathrm{M}_{\mathrm{M}}, \mathrm{n}_{\mathrm{M}}, \mathrm{q}_{\mathrm{Mt}}\left(\mathrm{q}_{\mathrm{Mgv}}\right), v\right)$ parameters describing $\eta_{M}$ and dependent on the mechanical and volumetric losses in the motor, the pressure losses $\Delta \mathrm{p}_{\mathrm{Mp}}=$ $=\mathrm{f}\left(\mathrm{Q}_{\mathrm{M}}, \mathrm{v}\right)$ in the channels must be determined with

$$
\mathrm{Q}_{\mathrm{M}}=\mathrm{q}_{\mathrm{Mt}}\left(\mathrm{q}_{\mathrm{Mgv}}\right) \mathrm{n}_{\mathrm{M}}+\mathrm{Q}_{\mathrm{Mv}}
$$

then intensity $\mathrm{Q}_{\mathrm{Mv}}=\mathrm{f}\left(\Delta \mathrm{p}_{\mathrm{Mi}}, \mathrm{n}_{\mathrm{M}}, v\right)$ of volumetric losses in the working chambers must be determined with

$$
\Delta \mathrm{p}_{\mathrm{Mi}}=\frac{2 \Pi\left(\mathrm{M}_{\mathrm{M}}+\mathrm{M}_{\mathrm{Mm}}\right)}{\mathrm{q}_{\mathrm{Mt}}\left(\mathrm{q}_{\mathrm{Mgv}}\right)}
$$

and the torque $\mathrm{M}_{\mathrm{Mm}}$ of mechanical losses in the ,shaft - working chambers" assembly must be determined as an $\mathrm{M}_{\mathrm{Mm}}=\mathrm{f}\left(\mathrm{M}_{\mathrm{M}}\right.$, $\left.\mathrm{n}_{\mathrm{M}}, \mathrm{q}_{\mathrm{Mt}}\left(\mathrm{q}_{\mathrm{Mgv}}\right), v\right)$ function.

The characteristic of the hydraulic motor overall efficiency $\eta_{M}=f\left(M_{M}, n_{M}, q_{M t}\left(q_{M g v}\right)\right.$, v) presents a complex 
picture as a product $\eta_{M m} \eta_{M v} \eta_{M p}$ of three efficiencies correctly described by:

mechanical efficiency $\eta_{M m}=f\left(M_{M}, n_{M}, q_{M t}\left(q_{M g v}\right), v\right)$,

volumetric efficiency $\eta_{M v}=f\left(\Delta p_{M i}, q_{M t}\left(q_{M g v}\right), n_{M}, v\right)$

and pressure efficiency $\eta_{M p}=f\left(\Delta p_{M i}, Q_{M}, v\right)$.

The picture of the hydraulic motor overall efficiency $\eta_{\mathrm{M}}=$ $=\mathrm{f}\left(\mathrm{M}_{\mathrm{M}}, \mathrm{n}_{\mathrm{M}}, \mathrm{q}_{\mathrm{Mt}}\left(\mathrm{q}_{\mathrm{Mgv}}\right), v\right)$ must be supplemented by assessment of the hydraulic motor operating field $\left(0 \leq \bar{\omega}_{M}\left\langle\bar{\omega}_{M \max }, 0 \leq \overline{\mathbf{M}}_{M}<\right.\right.$ $\left\langle\overline{\mathbf{M}}_{\mathbf{M} \text { max }}\right.$ ) in the hydrostatic drive system, i.e. assessment of the range of $\mathrm{n}_{\mathrm{M}}$ and $\mathrm{M}_{\mathrm{M}}\left(\overline{\boldsymbol{\omega}}_{\mathbf{M}}\right.$ and $\left.\overline{\mathbf{M}}_{\mathbf{M}}\right)$ parameters.

In the motor (and the hydrostatic drive system) $\left(0 \leq \bar{\omega}_{M}\left\langle\bar{\omega}_{M \max }\right.\right.$, $0 \leq \overline{\mathrm{M}}_{\mathrm{M}}\left\langle\overline{\mathrm{M}}_{\mathrm{Mmax}}\right)$ operating field, its current speed $\mathbf{n}_{\mathrm{M}}\left(\bar{\omega}_{\mathrm{M}}\right)$ and load $\mathbf{M}_{\mathbf{M}}\left(\mathbf{M}_{\mathbf{M}}\right)$ are an effect of the demand of the motor (system) driven machine (device) and are independent of the losses in the hydraulic motor and in the motor driving hydrostatic system.

However, the hydraulic motor (system) operating field limit values $\mathbf{n}_{M \max }\left(\bar{\omega}_{M_{\max }}\right)$ and $\mathbf{M}_{M_{\max }}\left(\overline{\mathbf{M}}_{M_{\max }}\right)$ depend on the maximum capacity of the hydraulic motor driving system. The values $\mathrm{n}_{\mathrm{M} \max }\left(\bar{\omega}_{\mathrm{Mmax}}\right)$ and $\mathrm{M}_{\mathrm{Mmax}}\left(\overline{\mathrm{M}}_{\mathrm{Mmax}}\right)$ determine simultaneously the corresponding motor energy efficiency $\eta_{M}$ and the overall system efficiency $\eta$.

The limit parameters of the hydrostatic drive system operation result from the pump theoretical capacity $Q_{P t}$ and the system nominal working pressure $p_{n}$ as well as from the actual energy losses in the hydraulic motor, conduits and pump and also losses in the motor speed throttling control assembly (if it is installed). Therefore, the limit values $\mathbf{n}_{M \max }\left(\bar{\omega}_{M \max }\right)$ and $\mathbf{M}_{M_{\max }}\left(\bar{M}_{M \max }\right)$ are also dependent on the working liquid viscosity $v$ changing in the $v_{\min } \leq v \leq v_{\max }$ range. The hydrostatically driven hydraulic motor operating field is also influenced by the $n_{P}=f\left(M_{P}\right)$ characteristic of the (electric or internal combustion) motor in the pump driving system.

\section{NECESSITY OF USE OF THE ENERGY LOSS MATHEMATICAL MODELS WITH THE LOSS COEFFICIENTS IN DISPLACEMENT MOTOR AND IN A HYDROSTATIC DRIVE SYSTEM}

Evaluation of the hydraulic motor overall efficiency $\eta_{M}=$ $=f\left(M_{M}, n_{M}, q_{M t}\left(q_{M g v}\right), v\right)$ as a product $\eta_{M m} \eta_{M v} \eta_{M p}$ of three motor efficiencies can be performed only by means of the mathematical models of losses and efficiencies, where the defined coefficients $k_{i}$ of energy losses in the motor and in the motor drive system are used.

Evaluation of the hydraulic motor energy efficiency is performed together with evaluation of the efficiency of a hydrostatic drive system where the hydraulic motor is used (including also the energy efficiency of pump, conduits and the hydraulic motor speed throttling control assembly (if it is used)).

In the proposed method, based on the mathematical models of losses, each kind of energy losses is a function of parameters directly influencing the losses and independent of those losses.

Evaluated are the values of the $k_{i}$ coefficients of energy losses, relating the mechanical, volumetric and pressure losses in the hydraulic motor, pump and other system elements to the reference values of driving system: nominal pressure $p_{n}$ of the system, theoretical capacity $\mathrm{Q}_{\mathrm{Pt}}$ of the system driving pump, theoretical torque $\mathrm{M}_{\mathrm{Pt}}$ of the pump shaft as well as theoretical torque $\mathrm{M}_{\mathrm{Mt}}$ of the hydraulic motor shaft. The $\mathbf{k}_{\mathrm{i}}$ coefficients are determined at the hydraulic oil reference viscosity $v_{n}$. At the same time the impact is determined of the viscosity ratio $v / v_{n}$ in the $v_{\min } \leq v \leq v_{\max }$ range on each kind of energy losses.

The method allows to evaluate the values and proportions of mechanical, volumetric and pressure losses in the hydraulic motor, pump, conduits and in the throttling assembly (if installed), as well as the dependence on the hydraulic oil viscosity $v$.

The energy investigations of a pump and hydraulic motor as independent displacement machines are limited to determination of the $k_{i}$ coefficients of losses in them. The energy efficiency characteristics of those machines are determined in parallel with efficiency evaluation of the hydrostatic drive system where they are used.

The knowledge of $\mathbf{k}_{\mathbf{i}}$ coefficients of the mechanical, volumetric and pressure losses in the drive system elements allows to obtain, with the numerical method, the characteristics of the hydrostatic drive system overall efficiency, pump efficiency, hydraulic motor efficiency, conduit efficiency and the motor speed throttling control assembly (if it is used) structural efficiency in the motor (system) $\left(0 \leq \bar{\omega}_{M}\left\langle\bar{\omega}_{M_{\max }}, 0 \leq \overline{\mathbf{M}}_{\mathbf{M}}\left\langle\overline{\mathbf{M}}_{\mathrm{Mmax}_{\max }}\right)\right.\right.$ operating field at a selected ratio $v / v_{n}$ of the hydraulic oil viscosity $v$ to the reference viscosity $v_{n}$.

Characteristics of the overall efficiency of elements used in a hydrostatic drive system: pump $\eta_{\mathrm{p}}$, hydraulic motor $\eta_{\mathrm{M}}$, conduits $\eta_{\mathrm{C}}$ and throttling control assembly (if it is used) structural efficiency $\boldsymbol{\eta}_{\text {st }}$ are defined as functions of the hydraulic motor (system) speed coefficient $\bar{\omega}_{M}$ and load coefficient $\overline{\mathbf{M}}_{M}$ and the hydraulic oil viscosity ratio $v / v_{n}$.

At the same time the hydraulic motor $\left(0 \leq \bar{\omega}_{M}\left\langle\bar{\omega}_{M \max }\right.\right.$,

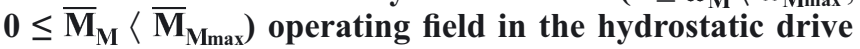
system is determined at the selected ratio $v / v_{n}$ of the hydraulic oil viscosity to the reference viscosity.

Characteristics of energy efficiency of the pump and hydraulic motor with the determined constant coefficients $\mathrm{k}_{\mathrm{i}}$ of losses and also of efficiency of the conduits are different in hydrostatic systems with different motor speed control structures.

The method is precise by definition and simple in use. It simplifies the laboratory investigation of pumps, hydraulic motors and hydrostatic drive systems. It allows to seek for energy saving solutions of pumps and hydraulic motors. It allows also to evaluate the overall energy efficiency of the drive and to find energy saving hydrostatic drive system structures.

\section{CONCLUSIONS}

1. Losses and energy efficiency of every drive motor and system must be presented as functions of physical quantities independent of losses in the motor and system. Such quantities are speed and load required by the machine or device driven by the motor, changing in the $\left(0 \leq \bar{\omega}_{M}<\bar{\omega}_{M \max }, 0 \leq \overline{\mathrm{M}}_{\mathrm{M}}<\overline{\mathrm{M}}_{\mathrm{Mmax}}\right)$ drive operating field. Speed and load of the motor decide of the instantaneous useful power of the motor and also in a differentiated way of kinds and values of losses occurring in the motor.

2. In energy considerations of a motor and a drive system, it is necessary to replace the Sankey diagram by the proposed diagram of power increase in the direction opposite to power flow.

3. It is necessary to determine the motor operating field in its drive system, i.e. to determine the motor speed coefficient $\bar{\omega}_{M}$ and load coefficient $\bar{M}_{M}$ dependent on and independent of losses in the motor and in the system.

4. The example of operation of a rotational displacement motor in a hydrostatic drive system shows a complex relation of 
energy losses in the motor and in the system to the motor shaft speed and load, to the capacity per one shaft revolution and to the working liquid viscosity. Evaluation of the motor overall efficiency $\eta_{M}$ as a product of mechanical efficiency $\eta_{\mathrm{Mm}}$, volumetric efficiency $\eta_{\mathrm{Mv}}$ and pressure efficiency $\eta_{\mathrm{Mp}}$ can be performed only by means of mathematical models of losses and efficiencies with the use of defined coefficients of losses in the motor and in the motor driving system.

5. The presented proposals open a new perspective of unavoidable research of drive motors and systems, making it possible to compare objectively the energy efficiency of different types of motors and drive systems.

\section{BIBLIOGRAPHY}

1. Paszota Z.: Graphical presentation of the power of energy losses and power developed in the elements of hydrostatic drive and control system. Part I-Rotational hydraulic motor speed series throttling control systems. Chapter in the monograph: ,, Research, design, production and operation of hydraulic systems" (in Polish), Adam Klich, Edward Palczak and Andrzej Meder editors. „Cylinder” Library. Komag Mining Mechanisation Centre, Gliwice 2008

2. Paszota Z.: Graphical presentation of the power of energy losses and power developed in the elements of hydrostatic drive and control system. Part II - Rotational hydraulic motor speed parallel throttling control and volumetric control systems. Chapter in the monograph: ,,Research, design, production and operation of hydraulic systems" (in Polish), Adam Klich, Edward Palczak and Andrzej Meder editors. „Cylinder” Library. Komag Mining Mechanisation Centre, Gliwice 2008

3. Paszota Z.: Direction of increase of power stream in the hydrostatic drive and control system. Graphical presentation of the power of energy losses and power developed in the elements of hydrostatic drive and control system. Part I - Rotational hydraulic motor speed series throttling control systems (in Polish), Napędy i sterowanie, scientific monthly, No 10 (114), October 2008

4. Paszota Z.: Direction of increase of power stream in the hydrostatic drive and control system. Graphical presentation of the power of energy losses and power developed in the elements of hydrostatic drive and control system. Part II - Rotational hydraulic motor speed parallel throttling control and volumetric control systems (in Polish), Napędy i sterowanie, scientific monthly, No 11 (115), November 2008

5. Paszota Z.: Graphical presentation of the power of energy losses and power developed in the elements of hydrostatic drive and control system. Part I - Rotational hydraulic motor speed series throttling control systems. Polish Maritime Research 3 (57) 2008, Vol. 15

6. Paszota Z.: Graphical presentation of the power of energy losses and power developed in the elements of hydrostatic drive and control system. Part II - Rotational hydraulic motor speed parallel throttling control and volumetric control systems. Polish Maritime Research 4 (58) 2008,Vol. 15

7. Paszota Z:: The operating field of a hydrostatic drive system. Chapter in the monograph: „Research, design, production and operation of hydraulic systems" (in Polish), Adam Klich, Antoni Kozieł and Edward Palczak editors. „Cylinder” Library. Komag Mining Mechanisation Centre, Gliwice 2009

8. Paszota Z.: Parameters of the energy efficiency investigations of pumps and hydraulic motors. The operating field of a hydrostatic drive system (in Polish), Napędy i sterowanie, scientific monthly, No 11 (127), November 2009

9. Paszota Z.: The operating field of a hydrostatic drive system parameters of the energy efficiency investigations of pumps and hydraulic motors. Polish Maritime Research 4 (62) 2009, Vol. 16

10.Paszota Z.: Energy losses in a rotational hydraulic motor definitions and relations for evaluation of the efficiency of motor and hydrostatic drive. Chapter in the monograph: ,, Research, design, production and operation of hydraulic systems" (in
Polish), Adam Klich, Antoni Kozieł and Edward Palczak editors. „Cylinder” Library. Komag Mining Mechanisation Centre, Gliwice 2010

11.Paszota Z.: Theoretical and mathematical models of the torque of mechanical losses in a hydraulic rotational motor for hydrostatic drive. Chapter in the monograph: ,, Research, design, production and operation of hydraulic systems" (in Polish), Adam Klich, Antoni Kozieł and Edward Palczak editors. „Cylinder” Library. Komag Mining Mechanisation Centre, Gliwice 2010

12.Paszota Z.: Energy losses in a rotational hydraulic motor definitions and relations for evaluation of the efficiency of motor and hydrostatic drive (in Polish), Napędy i sterowanie, scientific monthly, No 10 (138), October 2010

13.Paszota Z.: Theoretical and mathematical models of the torque of mechanical losses in a hydraulic rotational motor for hydrostatic drive (in Polish), Napędy i sterowanie, scientific monthly, No 11(139), November 2010

14.Paszota Z.: Energy losses in the hydraulic rotational motor - definitions and relations for evaluation of the efficiency of motor and hydrostatic drive. Polish Maritime Research 2 (65) 2010,Vol. 17

15.Paszota Z.: Theoretical and mathematical models of the torque of mechanical losses in a hydraulic rotational motor for hydrostatic drive. Polish Maritime Research 3 (66) 2010,Vol. 17

16.Paszota Z.: Hydrostatic drives as safe and energy saving machines (in Polish), Napędy i sterowanie, scientific monthly, No 1(141), January 2011

17.Paszota Z.: Hydrostatic drives as safe and energy saving machines (in Polish), Proceedings of the „Innovative machines and Technologies - Safety" conference, Szczyrk 03 - 04 February 2011

18.Paszota Z.: Hydrostatic drives as safe and energy saving machines. The drive investigation method compatible with the diagram of power increase opposite to the direction of power flow. Polish Maritime Research 1(68) 2011,Vol. 18

19.Paszota Z.: Theoretical and mathematical models of the torque of mechanical losses in the pump used in a hydrostatic drive. Polish Maritime Research 4(71) 2011, Vol. 18,

20.Paszota Z.: Effect of the working liquid compressibility on the picture of volumetric and mechanical losses in a high pressure displacement pump used in a hydrostatic drive. Part I Energy losses in a drive system, volumetric losses in a pump. International Scientific-Technical Conference Hydraulics and Pneumatics, Wrocław, 16 - 18 May 2012. Ośrodek Doskonalenia Kadr SIMP - Wrocław: ODK SIMP Wrocław, 2012,

21.Paszota Z.: Effect of the working liquid compressibility on the picture of volumetric and mechanical losses in a high pressure displacement pump used in a hydrostatic drive. Part II Mechanical losses in a pump /International Scientific-Technical Conference Hydraulics and Pneumatics, Wrocław, 16 - 18 May 2012 / Ośrodek Doskonalenia Kadr SIMP - Wrocław: ODK SIMP Wrocław, 2012,

22.Paszota Z.: Effect of the working liquid compressibility on the picture of volumetric and mechanical losses in a high pressure displacement pump used in a hydrostatic drive. Part I Energy losses in a drive system, volumetric losses in a pump. Polish Maritime Research 2(73), 2012, Vol.19,

23.Paszota Z.: Effect of the working liquid compressibility on the picture of volumetric and mechanical losses in a high pressure displacement pump used in a hydrostatic drive. Part II Mechanical losses in a pump. Polish Maritime Research 3(75), 2012, Vol.19.

\section{CONTACT WITH THE AUTHOR}

Prof. Zygmunt Paszota

Faculty of Ocean Engineering and Ship Technology

Gdansk University of Technology Narutowicza 11/12

80-233 Gdansk, POLAND

e-mail: zpaszota@pg.gda.pl 